\title{
Sudden Deafness: The Missing Questions and Data
}

Although sudden deafness is common, its etiology and pathology are still hypothetical, and the efficiency of treatments remains questionable. There are other questions remaining unanswered. If sudden deafness is caused by a virus as common as the herpes simplex virus, why is it so rare? Why is sudden deafness seldom associated with an a frigore facial paralysis or with vestibular neuritis? Why is the onset of the deficit so abrupt and the recovery so slow? Why has the incidence not increased in the population suffering from AIDS? Why can sudden deafness be the first manifestation of an acoustic neuroma? Why are inner-ear traumatic procedures such as a sacculotomy or cochleosacculotomy not always followed by a hearing loss, which does occur but only in one third of cases and usually with a delay of several hours or days? Indeed, very little is known about sudden deafness.

Facing such a mysterious disorder, it would appear logical to accumulate as many data as possible and to publish them so that scientists can use them for comparison with their own data. However, comparisons are difficult be- cause diagnostic criteria, evaluation of hearing loss and recovery are not standardized and also because most reports do not give sufficient information. Most often, the data have been classified and analyzed in such a way that the recovery of the hard data is not possible.

This issue of Otorhinolaryngologia Nova intends to help clarify some aspects of the topic. Invited experts seem to agree on some points, i.e. no treatment has yet been proven efficient, sudden deafness is not considered as a therapeutic emergency and therapeutic abstention represents a correct choice from an ethical point of view. They also consider that many factors can influence the course of the disease and that clinical trials are limited by too small numbers of cases that can be evaluated in a single institution within a reasonable period of time. They suggest to initiate multicentric and international studies with strict criteria. We hope this issue will stimulate such a collaboration.

Jean-Philippe Guyot, Geneva

\section{KARGER}

๑) 2000 S. Karger AG, Basel

Fax + 41613061234

E-Mail karger@karger.ch www. karger.com
Accessible online at: www.karger.com/journals/orn 